\title{
SSynthesis
}

International Scientific Conference of IT and Business-Related Research

\section{OPSTANAK MALIH I SREDNJIH PREDUZEĆA U USLOVIMA OTEŽANOG PRIVREĐIVANJA}

\section{THE SURVIVAL OF SMALL AND MEDIUM-SIZED ENTERPRISES IN DIFFICULT BUSINESS CONDITIONS}

\author{
Nino Vesković \\ Univerzitet Singidunum, Poslovni fakultet u Beogradu, Beograd, Srbija
}

\begin{abstract}
Apstrakt:
Mala i srednja preduzeća predstavljaju tradicionalan način poslovanja koji nudi brojne prednosti, poput poboljšane stope zaposlenosti nisko i visoko kvalifikovane radne snage, u smislu trajne uposlenosti, brži ukupni rast i razvoj samog sektora sa dinamičnijom transformacijom ka ravnomernijem lokalnom i regionalnom razvoju. Na osnovu statističkih podataka Privredne komore Republike Srbije (PKRS) evidentno je da tokom 2013. godine od ukupnog broja pravnih lica u privredi Republike, 99,8\% odlazi na mala i srednja preduzeća, s obzirom da ona čine $34 \%$ BDP, i učestvuju sa $44,5 \%$ u ukupnom izvozu i sa $66,5 \%$ u ukupnom broju zaposlenih. Međutim, mala i srednja preduzeća (MSP) su suočena sa brojnim problemima koji su prouzrokovani ekonomskom krizom, a koje bi trebalo prevazići Nacionalnom strategijom.
\end{abstract}

\section{Ključne reči:}

mala i srednja preduzeća (MSP), zaposlenost, dinamičnost, rast i razvoj.

\section{UVOD}

Privrede gotovo svih razvijenih zemalja sveta prepoznaju segment malih i srednjih preduzeća (MSP) kao najznačajniji (Erić et al., 2012). Ovaj rad polazi od osnovne hipoteze da su MSP korisna za privredni razvoj Republike Srbije (RS), i pomoćnih hipoteza koje kažu da ovaj segment nudi stabilan izvor: novih radnih mesta, povećanu zaposlenost, preduslov za poboljšanje standarda, blagostanja, inovacije, povećanje poreskih prihoda kroz smanjenje neformalne odnosno sive ekonomije. MSP su fleksibilna, i pomažu da se brže i efikasnije izvrši prilagođavanje turbulentim promenama na tržištu uspevajući da svojim uslugama/proizvodima zadovolje posebne potrebe, tražnju i očekivanja potrošača. Mnoga od njih, a naročito trgovinske radnje, deluju mahom lokalno. Isto tako, MSP na nacionalnom nivou doprinose privrednom razvoju i utiču na smanjenje siromaštva tako da predstavljaju značajan faktor globalnog poslovanja, što predstavlja dopunu glavnoj hipotezi (Erić et al., 2012).

\section{REZULTATI}

Republička agencija za razvoj malih i srednjih preduzeća i preduzetništva tokom 2008. godine je sprovela istraživanje po kom se vidi neravnomerna zastupljenost MSP po granama delatnosti. Prema navedenom istraživanju sektor trgovine zauzi-

\section{Abstract:}

Small and medium-sized enterprises (SME) represent the traditional way of doing business, which offers numerous advantages such as improved employment rates of the low and highly skilled workforce, in terms of permanent employment, faster overall growth and development of the sector with a more dynamic transformation towards a more balanced local and regional development. According to statistics of the Chamber of Commerce of the Republic of Serbia (SCRS) for the year 2013, it can be observed that out of the total number of legal entities of the entire Serbian economy, $99,8 \%$ goes to SME, as they account for $34 \%$ of GDP, $44,5 \%$ of total exports and $66,5 \%$ of the total number of employees. However, SME face numerous problems triggered by the economic crisis that could be overcome by the National Strategy.

\section{Key words:}

small and medium-sized enterprises (SME), employment, dynamics, growth and development.

ma drugo mesto, dok je u 2012. godini primetno povećanje u sektorima trgovine na veliko i malo, i iznosi ukupno 27\% (Poslodavci, 2012). Podaci su predstavljeni u tabeli sastavljenoj na osnovu datog istraživanja:

\begin{tabular}{|l|c|c|}
\hline \multicolumn{1}{|c|}{ Delatnost MSP } & Udeo u \% 2008. & Udeo u \% 2012. \\
\hline Proizvodnja i prerada & $35,54 \%$ & $13,17 \%$ \\
\hline Trgovina na malo & $14,85 \%$ & $27 \%$ zajedno \\
\hline Trgovina na veliko & $9,31 \%$ & $27 \%$ zajedno \\
\hline
\end{tabular}

Tabela 1. Zastupljenost po granama delatnosti MSP, 2008/2012

Iz gorenavedenog se može videti da podršku procesu poznatom kao samozapošljavanje predstavljaju sredstva koja svaki nezaposleni građanin RS može da ostvari u vidu subvencija za nabavku osnovnih sredstava i slično, vezanih za realizaciju biznis plana (Erić et al., 2012). Postoji mogućnost otvaranja novih radnih mesta, jer je sektor nosilac privrednog rasta i razvoja, sa dinamičnim rastom zaposlenosti od 24,9\% (Erić et al., 2012). Nacionalna strategija razvoja Republike Srbije predvidela je da bi na godišnjem nivou, broj novootvorenih malih i srednjih preduzeća trebalo da bude za 10.000 veći od broja zatvorenih preduzeća. Takođe, Republika Srbija bi do kraja 2015. godine trebalo da ima oko 150.000 aktivnih MSP koja će zapošljavati 
oko dva miliona građana (Bizlife, 2014). Stiče se utisak da posebna pažnja treba da bude usmerena na: omladinu, pojedince sa nižim stepenom obrazovanja, pojedince starije od 50 godina (Erić et al., 2012).

Osim toga, Vlada Republike Srbije je u okviru Nacrta strategije za podršku razvoju malih i srednjih preduzeća, preduzetništva i konkurentnosti u periodu 2015 - 2020 predočila novi, veoma optimističan plan zapošljavanja u sektoru MSP. Pored toga, Vlada RS je pripremila još dva dokumenta koja će se baviti podsticajem razvoja MSP i očekuje se da će oni biti usvojeni početkom 2015. godine. Cilj ove strategije je da Srbija obezbedi dostupnije izvore finansiranja za ovaj sektor i da pruži podršku kontinuiranom razvoju ljudskih resursa i sektora obrazovanja, čime se dokazuje glavna hipoteza. Potom, strategija bi trebalo da jača održivost i konkurentnost ovog sektora, da unapredi pristup novim tržištima, da podstakne razvoj i promociju preduzetničkog duha i da podstakne zapošljavanje žena, omladine i jednom rečju društva uopšte, čime su dokazane pomoćne hipoteze. Prema statistikama Privredne komore Srbije (PKS) tokom 2013. godine od ukupnog broja pravnih lica u privredi Republike Srbije 99,8\% odlazi na mala i srednja preduzeća, $34 \%$ čini BDP, $44,5 \%$ učestvuje u izvozu, i $66,5 \%$ u ukupnom broju zaposlenih. Normativi vezani za poslovanje MSP bi trebalo da budu usklađeni sa onima koji postoje u Evropskoj uniji. Prema Nacrtu strategije za podršku razvoju malih i srednjih preduzeća i u skladu sa jednim od ciljeva Organizacije za ekonomsku saradnju i razvoj (OECD) Republika Srbija bi trebalo da omogući pomoć i dobro poslovno okruženje državi i privredi. Shodno tome, OECD ostvaruje stalnu komunikaciju i saradnju sa državnim institucijama na lokanom-regionalnom nivou, što ide u prilog dokazivanju osnovne hipoteze: Obezbediti okruženje pogodno za poslovanje ovog sektora kao i za razvoj njegove inovativnosti i konkurentnosti, što bi trebalo da omogući prenošenje znanja i iskustava koja dolaze iz inostranstva. Međunarodna saradnja podstiče inovativnost (u ovakvom vidu poslovanja leži naša budućnost); ulaže u razvoj veština i unapređenje objedinjene tehnologije; razvija sistem stalne edukacije i treninga; koristi kvalifikovanu radnu snagu; organizuje međunarodne kontakte za primenu novih tehnologija, i za zajednička ulaganja; doprinosi organizaciji klastera kako bi se udružila sredstva namenjena razvoju i istraživanju (Mijačić, 2011).
2013. GODINA

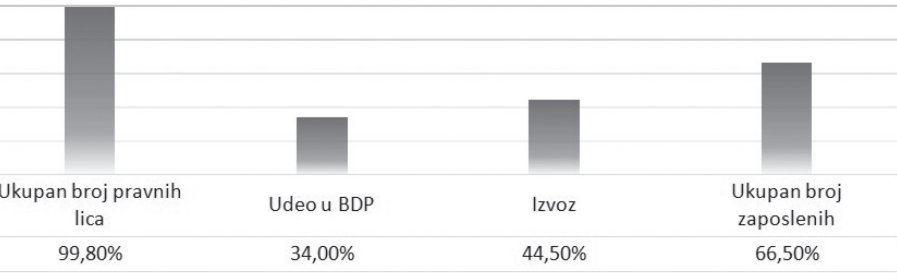

Slika 1: Stanje MSP u privredi RS tokom 2013. godine

Izvor: Autor, na osnovu navedenih podataka u radu

\section{ZAKLJUČAK}

Funkcionisanje malih i srednjih preduzeća u Republici Srbiji vezano je za veliki broj nagomilanih problema, pa je neophodno sprovesti smernice nove državne regulative, čime će se omogućiti ozbiljnija i dugoročnija tržišna egzistencija. Na ovaj način uspešno smo dokazali hipotezu, koja je postavljena u uvodnom delu rada, po kojoj su MSP korisna za privredni razvoj Republike Srbije. Ovaj privredni segment nudi stabilan izvor novih radnih mesta, koja predstavljaju preduslov za poboljšanje standarda, povećanje poreskih prihoda kroz smanjenje neformalne odnosno sive ekonomije, što daje podstrek sticanju i proširivanju znanja.

\section{LITERATURA}

Bizlife. (2014). Optimističan plan zapošljavanja u sektoru MSP. Dostupno na http://www.bizlife.rs/vesti/75049-optimistican-plan-zaposljavanja-u-sektoru-msp. Pristup 22.12.2014.

Erić, D., Beraha, I., Đuričin, S., Kecman, N., \& Jakišić, B. (2012). Finansiranje malih i srednjih preduzeća u Srbiji. Dostupno na http://www.pks.rs/SADRZAJ/Files/Biro\%20za\%20saradnju\%20sa\%20EU/Finansiranje\%20MSP\%20u\%20Srbiji.pdf (Pristup 22.12.2014.)

Mijačić, D. (2011). Programi podrške malim i srednjim preduzećima preduzetništvu u Republici Srbiji. Dostupno na http://www. lokalnirazvoj.org/upload/Publication/Document/2011_11/ Programi_podrske_MSP_i_preduzetnicima_u_Republici_Srbiji.pdf. Pristup 22.12.2014.

Poslodavci. (2012). Neuspeh politike razvoja malih i srednjih preduzeća. Dostupno na: http://www.poslodavci.rs/vesti/neuspeh-politike-razvoja-malih-i-srednjih-preduzeca?id=74. Pristup 22.12.2014. 